\title{
Advertising patterns of a fast-food chain on social media in Brazil
}

\author{
Jéssica Moreira da Silva ${ }^{1}$, Juliana de Paula Matos ${ }^{1}$, Michele Bittencourt Rodrigues' ${ }^{1}$, \\ Laís Amaral Mais², Rafael Moreira Claro and Paula Martins Horta ${ }^{1, *}$ \\ 'Departamento de Nutrição, Universidade Federal de Minas Gerais (UFMG), Avenida Professor Alfredo Balena 190, \\ Belo Horizonte 30130-100, Brazil: ${ }^{2}$ Instituto Brasileiro de Defesa do Consumidor (IDEC), São Paulo, Brazil
}

Submitted 30 March 2021: Final revision received 17 November 2021: Accepted 13 December 2021: First published online 23 December 2021

\begin{abstract}
Objective: To investigate the advertising patterns on the posts of a fast-food chain in Brazil on three social media platforms in 2019.

Design: An exploratory cross-sectional study.

Setting: Advertising strategies on the posts of a major fast-food chain on their official Facebook, Instagram and YouTube accounts. The strategies were investigated according to the INFORMAS protocol for food promotion monitoring. Principal component analysis (PCA) was employed to identify advertising patterns in each platform.

Participants: 305 advertisements

Results: Four advertising patterns were identified in the PCA of Facebook and Instagram. In both platforms, the components for kids and product exaltation were similar. On Facebook, a pattern corresponding to economic appeal was identified as price and discount, while on Instagram, this pattern also included a practical approach. On Facebook, the fourth component was named celebrity, while on Instagram it was celebrity/innovation since on this second social media the component also included the 'new brand development' variable. On YouTube, three advertising patterns were identified in PCA. Similar to the other platforms, the first and the second patterns were called for kids and price and discount, and the third component referred to both celebrity and commemorative dates. Conclusions: The advertising patterns of the fast-food chain on three social media platforms were commonly directed to children and addressed price, discounts and the celebrities' universe. The findings of this study corroborate other data in the literature regarding unhealthy food advertising on social media. This study discusses the urgency of regulating food advertising content on this medium.
\end{abstract}

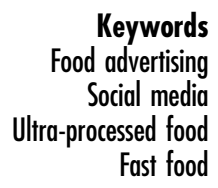

Consumption of ultra-processed food has increased in Brazil over the last few years and is replacing home-made dishes in the Brazilian diet ${ }^{(1,2)}$. Ultra-processed food contains high amounts of sodium, fats, sugars and food additives, and its excessive intake is associated with noncommunicable diseases, such as obesity, CVD, cancer, among others ${ }^{(3)}$. Ultra-processed foods are widely available, easy to transport and store, ready-to-heat/ready-toeat and hyper-palatable ${ }^{(3)}$. These characteristics make these products convenient and practical to eat ${ }^{(3,4)}$.

In order to enhance sales and acquire new customers, ultra-processed food companies use multiple types of media for advertising their products ${ }^{(5,6)}$. Individuals' exposure to advertising content can influence their food consumption by increasing brand awareness and purchase intention $^{(7)}$. Although all individuals can be influenced by the persuasive power of marketing communication ${ }^{(8)}$, children and adolescents are the most vulnerable groups because they possess limited cognitive abilities to differentiate an informative tone from commercial content ${ }^{(9,10)}$.

On social media, the persuasive potential of the commercial message is high because of the large number of individuals that use these platforms and the presence of highly interactive tools in posts, such as links, direct conversation, hashtags and other engagement elements ${ }^{(11)}$. In addition, characteristics of peer endorsement and lack of 
explicit advertising cues presented in some forms of digital media make digital marketing even more impactful on subjects' food behaviour than those in traditional marketing $^{(8)}$.

In Brazil, $75 \%$ of internet users have accounts on Facebook, YouTube, Twitter, Instagram and other platforms $^{(12,13)}$ and 16 of the 250 most popular Facebook pages in Brazil are those of ultra-processed food brands ${ }^{(14)}$. In addition, a recent study found that ultra-processed food companies are the main food companies that advertise on TV, Facebook, Instagram and YouTube in Brazil, and the message broadcasted by these brands varies across the media according to the advertising strategies used ${ }^{(15)}$. Despite this, little is known about the advertising patterns of food on social media platforms. This knowledge is necessary to generate evidence to understand the extent of the problem of food advertising exposure and to determine appropriate and effective policy responses ${ }^{(16)}$.

This study aimed to investigate the advertising patterns present on the posts of the most popular fast-food chain in Brazil on three social media platforms in 2019. The company in this study has a great diversity of ultraprocessed foods on its portfolio and is the world's leading foodservice brand, with more than 36000 restaurants in more than 100 countries. In Brazil, the company has 1026 restaurants located in all 26 states, and a survey carried out with 1998 Brazilian Internet users in October 2019 demonstrated that $73 \%$ of the respondents had bought food from this company in the previous twelve months ${ }^{(17)}$.

\section{Methods}

This is an exploratory cross-sectional study that comprised all posts made by the most popular fast-food chain in Brazil on its official pages on Facebook, Instagram and YouTube from January 1 to December 31, 2019. These social media platforms are the most popular in the country ${ }^{(12,13)}$. Facebook is a social media platform that allows people to build public profiles and establish explicit connections with others in their social media, Instagram is a platform that provides users with video- and photo-sharing possibilities, and YouTube is a video-sharing platform ${ }^{(18)}$. All posts were collected from the official pages in a single moment using a screen capture tool and saved as PDF files for further analysis. All shortlisted videos were viewed using the Google Chrome browser. While the videos and ads played within the browser, they were recorded with an on-screen recorder.

All posts were analysed regarding the presence and type of food items: if they were ultra-processed or not, based on NOVA classification ${ }^{(3)}$. We considered a food item to be present in the post when a representation of food was available, such as in a cartoon or as a picture in the scene or when real food was shown.

Advertising strategies were investigated based on the INFORMAS (International Network for Food and Obesity/non-communicable diseases Research, Monitoring and Action Support) protocol for food promotion monitoring on television ${ }^{(19)}$. INFORMAS is a global network of public interest organisations and researchers that aims to monitor, benchmark and support public and private sector actions to increase healthy food environments and reduce obesity and non-communicable diseases and their related inequalities (www.informas.org). The INFORMAS framework consists of 10 modules related to food environment dimensions, including food promotion.

Advertising strategies from the INFORMAS protocol were further classified into three categories: the power of advertising ( $n$ 10) (e.g. use of licensed character, celebrities, awards, etc), premium offers ( $n$ 9) (e.g. pay 2 take 3 or more, gifts or collectable, limited edition, etc) and brand benefit claims ( $n$ 8) (e.g. messages that exalt sensory-based characteristics such as flavour, taste, aroma and recommend how to use/consume the product, etc) ${ }^{(19)}$, as described in Table 1. Although the INFORMAS protocol has been specifically proposed for food advertising monitoring on $\mathrm{TV}^{(19)}$, the variables present in this protocol have been used in other studies that have monitored food advertising on social media(15,20-22).

Table 1 Advertising strategies investigated

\begin{tabular}{|c|c|c|}
\hline Power of advertising & Premium offers & Brand benefit claims \\
\hline $\begin{array}{l}\text { - Cartoon/Company-owned character e.g. M\&Ms } \\
\text { - Licensed character e.g. Dora the explorer } \\
\text { - Amateur sportsperson e.g. person playing a sport } \\
\text { - Celebrity (non-sports) e.g. Jamie Oliver } \\
\text { - Movie tie-in e.g. Shrek } \\
\text { - Famous sportsperson/team e.g. All Blacks } \\
\text { - Non-sports/historical events/festivals e.g. Christmas, } \\
\text { Anzac Day } \\
\text { - 'For kids' e.g. image of a child, 'great for school lunches', } \\
\text { 'for school lunchboxes } \\
\text { - Awards e.g. Best Food Award 2014, award-winning, } \\
\text { number one best-selling' } \\
\text { - Sports event }\end{array}$ & $\begin{array}{l}\text { - Game and app } \\
\text { downloads } \\
\text { - Contests } \\
\text { - Pay } 2 \text { take } 3 \text { or } \\
\text { other } \\
\text { - } 20 \% \text { extra or other } \\
\text { - Limited edition } \\
\text { - Social charity } \\
\text { - Gift or collectable } \\
\text { - Price discount } \\
\text { - Loyalty program }\end{array}$ & $\begin{array}{l}\text { - Sensory based characteristics (taste, texture, } \\
\text { appearance, aroma) } \\
\text { - New brand development } \\
\text { - Suggested use (e.g. great for lunchboxes) } \\
\text { - Suggested users are children or the whole family } \\
\text { - Emotive claims (fun, feelings, popularity) } \\
\text { - Puffery (claiming to be advantageous over other } \\
\quad \text { products) } \\
\text { - Convenience } \\
\text { - Price }\end{array}$ \\
\hline
\end{tabular}

Source: Kelly, 2017. 
Data were independently tabulated by two researchers using Microsoft ${ }^{\circledR}$ Excel 2010, and all inconsistencies were subsequently verified and resolved by a third researcher. Statistical analyses were performed using the statistical software, Stata, version 12.1.

First, the proportion of advertising strategies on each social media was described, and differences were tested using the chi-square test on 22 identified variables that had proportions greater than 0 in at least one of the assessed social media. Because there were multiple comparisons for each advertising strategy among the three social media platforms, statistical differences were considered when $P<0.01$.

Then, principal component analysis (PCA) was employed to investigate the behaviour of the strategies used for food advertising in each platform. All strategies with a frequency of at least $10 \%$ on each social media were included in the analysis. Components with eigenvalues greater than 1.0 were retained, following Kaiser's criteria. Negative factor loadings indicated that the strategy was inversely associated with the component, while positive factor loadings indicated a direct association. Variables with factor loadings $\geq 0.30$ (when positive) or $\leq-0.30$ (when negative) were considered significantly associated with the component. Therefore, the greater the magnitude of the factor loading, the greater its contribution to the pattern. PCA is a technique for reducing the dimensionality of datasets, increasing interpretability but at the same time minimising information loss. This is done by creating new uncorrelated variables that successively maximise variance $^{(23)}$. In this study, PCA was used to create uncorrelated advertising patterns and synthesise the use of marketing strategies on social media posts. The use of PCA in studying food advertising patterns has also been applied in TV food marketing monitoring ${ }^{(24,25)}$.

\section{Results}

The fast-food chain published 305 advertisements on its official pages on Facebook ( $n$ 150), Instagram ( $n$ 110) and YouTube ( $n$ 45) in Brazil in 2019.

Most of the posts (82.2\%) contained a representation of a food item or a real food image. Among them, 6 (2.4\%) were not of ultra-processed foods and referred to coffee or an advertisement of a reality show supported by the brand in which chefs are cooking unprocessed foods. When an image or a representation of ultra-processed food was present ( $n$ 245; 97.6\%), the majority were images of real products ( $n$ 238) and seven were representations of ultra-processed foods (cartoons, for example). Posts that did not show food mainly referred to sustainability themes, social responsibility actions coordinated by the company or advertisements of toys.

Advertising strategies from the power of the advertising group were more frequent on YouTube (66.7\%) than those on Facebook ( $43.3 \%)$ and Instagram $(39.1 \%)(P=0.006)$.
The presence of 'cartoon/company-owned character' $(P<0.001)$, 'for kids' $(P<0.001)$, 'licensed character' $(P=0.001)$ and 'movie tie-in' $(P=0.007)$ prevailed on YouTube in comparison with the other two platforms. Similarly, premium offers strategies were more common on YouTube $(57.8 \%)$ than those on Facebook (38.7\%) and Instagram $(30.0 \%)(P=0.005)$, going by the high number of 'gifts' or 'collectables' on the streaming video platform $(P<0.001)$. Brand benefit claims strategies were present on $100 \%$ of YouTube videos in comparison to $81.3 \%$ on Facebook posts and $86.4 \%$ on Instagram posts $(P=0.007)$. From this group of advertising strategies, 'suggested users are children or whole family' $(P=0.001)$, and 'emotive claims' $(P<0.001)$ were more frequent on YouTube advertisements than those on the posts on the other social media platforms (Table 2). Examples of the brand posts that used the advertising strategies under study are provided in the Supplementary Material.

Four advertising patterns were identified in the PCA of Facebook. The first one was for kids and was positively correlated with 'cartoon/company-owned character'; 'for kids', 'licensed character', 'movie tie-in', 'limited edition', 'gift or collectable', and 'suggested users are children or the whole family'. The second component was price and discount and was positively correlated with 'price discount' and 'price' claims. The third was product exaltation and was positively correlated with 'sensory-based characteristics' and 'new brand development' and negatively correlated with 'non-sports/historical events/festivals'. The fourth component was celebrity and was positively correlated with 'celebrity (non-sports)', 'sensory-based characteristics' and 'emotive claims'. PCA explained $77.0 \%$ of the combined variability (Table 3 ).

Similarly, on Instagram, PCA resulted in four advertising patterns. First, for kids, was correlated with the same variables as the corresponding component on Facebook, except for 'cartoon/company-owned character' and 'movie tie-in'. The second was practical/price and discount and was correlated with 'price discount', 'limited edition', 'convenience' and 'emotive claims'. The third was product exaltation and correlated with the same variables as the corresponding component on Facebook. The fourth component was celebrity/innovation and was positively associated with 'celebrity', 'sensory-based characteristics', 'new brand development' and 'emotive claims' and inversely correlated with 'price discount'. PCA explained $71.7 \%$ of the combined variability (Table 4 ).

On YouTube, three advertising patterns were identified in the PCA. The first and second patterns were for kids and price and discount, respectively, and were correlated with the same variables as on Facebook's corresponding advertising patterns. The third component referred to both celebrity and commemorative dates and was positively correlated with 'celebrity', 'non-sports/historical events/ festivals' and 'emotive claims'. PCA explained $71.3 \%$ of the combined variability (Table 5). 
Table 2 Proportion of advertising strategies on posts published by a fast-food chain on its social media platforms (Facebook, Instagram and YouTube) in Brazil, 2019

\begin{tabular}{|c|c|c|c|c|}
\hline Advertising strategy & Facebook ( $n$ 150) & Instagram (n 110) & YouTube ( $n$ 45) & $P$-value \\
\hline Power of advertising & $43 \cdot 3$ & $39 \cdot 1$ & $66 \cdot 7$ & 0.006 \\
\hline Celebrity (non-sports) & $13 \cdot 3$ & $17 \cdot 3$ & $22 \cdot 2$ & 0.331 \\
\hline Cartoon/company-owned character & $11 \cdot 3$ & $5 \cdot 5$ & $28 \cdot 9$ & $<0.0001$ \\
\hline Sports event & 0.0 & 0.0 & 0.0 & - \\
\hline 'For kids' & $18 \cdot 7$ & $11 \cdot 8$ & $42 \cdot 2$ & $<0.0001$ \\
\hline Licensed character & $17 \cdot 3$ & $10 \cdot 0$ & $35 \cdot 6$ & 0.001 \\
\hline Famous sportsperson/team & 0.0 & 0.0 & 0.0 & - \\
\hline Amateur sportsperson & 0.0 & 0.0 & 0.0 & - \\
\hline Non-sports/historical events/festivals & $16 \cdot 7$ & $14 \cdot 6$ & $13 \cdot 3$ & 0.821 \\
\hline Movie tie-in & $12 \cdot 0$ & $8 \cdot 2$ & $26 \cdot 7$ & 0.007 \\
\hline Awards & 0.7 & $1 \cdot 8$ & $2 \cdot 2$ & 0.610 \\
\hline Premium offers & 38.7 & $30 \cdot 0$ & $57 \cdot 8$ & 0.005 \\
\hline Price discount & $10 \cdot 0$ & $10 \cdot 0$ & $11 \cdot 1$ & 0.974 \\
\hline Contests & 0.0 & 0.0 & 0.0 & - \\
\hline Limited edition & $25 \cdot 3$ & $20 \cdot 9$ & $37 \cdot 8$ & 0.091 \\
\hline Gift or collectable & $16 \cdot 7$ & $10 \cdot 0$ & $37 \cdot 8$ & $<0.0001$ \\
\hline Loyalty program & 0.0 & 0.0 & 0.0 & - \\
\hline Pay 2 take 3 or other & $4 \cdot 0$ & $2 \cdot 7$ & 0.0 & 0.375 \\
\hline Game and app downloads & 0.0 & 0.0 & 0.0 & - \\
\hline $20 \%$ extra or other & 0.0 & 0.0 & 0.0 & - \\
\hline Social charity & $6 \cdot 0$ & 5.5 & 4.4 & 0.921 \\
\hline Brand benefit claims & $81 \cdot 3$ & $86 \cdot 4$ & $100 \cdot 0$ & 0.007 \\
\hline Sensory based characteristics & $58 \cdot 0$ & $69 \cdot 1$ & $75 \cdot 6$ & 0.045 \\
\hline Suggested use & 4.7 & $7 \cdot 3$ & $2 \cdot 2$ & 0.399 \\
\hline New brand development & $19 \cdot 3$ & 23.6 & $22 \cdot 2$ & 0.695 \\
\hline Price & $10 \cdot 0$ & $9 \cdot 1$ & $11 \cdot 1$ & 0.925 \\
\hline Puffery & 0.0 & 0.0 & 0.0 & - \\
\hline Suggested users are children or the whole family & $18 \cdot 7$ & $10 \cdot 9$ & $37 \cdot 8$ & 0.001 \\
\hline Convenience & $7 \cdot 3$ & $10 \cdot 9$ & $17 \cdot 8$ & 0.120 \\
\hline Emotive claims & 34.7 & 38.2 & 88.9 & $<0.001$ \\
\hline
\end{tabular}

${ }^{*} \chi^{2}$ test with significance at $1 \%(P<0.01)$.

Table 3 Factor loadings for advertising strategies used by a fast-food chain on its official posts on Facebook, according to four components in Brazil, 2019

\begin{tabular}{lrrrr}
\hline & \multicolumn{3}{c}{ Component } \\
\cline { 2 - 5 } Advertising strategy & For kids & Price and discount & Product exaltation & Celebrity \\
\hline Power of advertising & & & \\
Celebrity (non-sports) & -0.07 & -0.10 & -0.21 & $\mathbf{0 . 7 2}$ \\
Cartoon/company-owned character & $\mathbf{0 . 3 5}$ & 0.04 & 0.13 & 0.04 \\
'For kids' & $\mathbf{0 . 3 9}$ & -0.01 & -0.03 & 0.01 \\
Licensed character & $\mathbf{0 . 3 6}$ & 0.00 & 0.11 & 0.02 \\
Non-sports/historical events/festivals & 0.00 & -0.19 & $-\mathbf{0 . 5 8}$ & -0.05 \\
Movie tie-in & $\mathbf{0 . 3 5}$ & 0.02 & 0.08 & 0.01 \\
Premium offers & & & & 0.00 \\
Price discount & -0.07 & 0.67 & 0.07 & -0.15 \\
Limited edition & $\mathbf{0 . 3 0}$ & 0.16 & 0.01 & 0.00 \\
Gift or collectable & $\mathbf{0 . 3 9}$ & 0.01 & $\mathbf{0 . 5 0}$ & $\mathbf{0 . 3 1}$ \\
Brand benefit claims & & & $\mathbf{0 . 5 6}$ & -0.11 \\
Sensory-based characteristics & -0.19 & 0.05 & -0.07 & 0.00 \\
New brand development & -0.11 & -0.16 & -0.01 & 0.06 \\
Price & -0.07 & $\mathbf{0 . 6 7}$ & 0.06 & $\mathbf{0 . 5 8}$ \\
Suggested users are children or whole family & $\mathbf{0 . 3 7}$ & 0.00 & & \\
Emotive claims & 0.16 & 0.09 & & \\
\hline
\end{tabular}

Note: The values in bold represent a correlation greater than 0.30 or lesser than -0.30 .

\section{Discussion}

This study showed the advertising patterns present on posts published by a popular fast-food chain on its official pages on social media in Brazil. Although exploratory and restricted to one brand, the findings of this study corroborate other data in the literature that show the predominance of unhealthy food advertising on social media, and this discusses the urgency of regulating food advertising content on this medium ${ }^{(14,15,20,26-29)}$. These studies applied different protocols to collect advertising strategies and classify food items. 
Table 4 Factor loadings for advertising strategies used by a fast-food chain on its official posts on Instagram, according to four components in Brazil, 2019

\begin{tabular}{|c|c|c|c|c|}
\hline \multirow[b]{2}{*}{ Advertising strategy } & \multicolumn{4}{|c|}{ Component } \\
\hline & For kids & Practical/Price and discount & Product exaltation & Celebrity/Innovation \\
\hline \multicolumn{5}{|l|}{ Power of advertising } \\
\hline Celebrity (non-sports) & $-0 \cdot 10$ & 0.17 & -0.26 & 0.55 \\
\hline 'For kids' & 0.47 & -0.09 & -0.01 & 0.07 \\
\hline Licensed character & 0.40 & -0.13 & 0.10 & $0 \cdot 10$ \\
\hline Non-sports/historical events/festivals & 0.03 & 0.02 & -0.63 & 0.08 \\
\hline \multicolumn{5}{|l|}{ Premium offers } \\
\hline Price discount & -0.01 & 0.56 & 0.18 & -0.37 \\
\hline Limited edition & 0.32 & 0.30 & 0.29 & -0.08 \\
\hline Gift or collectable & 0.47 & -0.06 & 0.05 & $0 \cdot 10$ \\
\hline \multicolumn{5}{|l|}{ Brand benefit claims } \\
\hline Sensory-based characteristics & -0.17 & 0.10 & 0.44 & 0.46 \\
\hline New brand development & -0.15 & -0.25 & 0.41 & 0.38 \\
\hline Suggested users are children or whole family & 0.46 & $-0 \cdot 11$ & 0.03 & 0.05 \\
\hline Convenience & 0.05 & 0.56 & 0.04 & 0.13 \\
\hline Emotive claims & 0.15 & 0.36 & -0.23 & 0.39 \\
\hline
\end{tabular}

Note: The values in bold represent a correlation greater than 0.30 or lesser than -0.30 .

Table 5 Factor loadings for advertising strategies used by a fast-food chain on its official posts on YouTube, according to three components in Brazil, 2019

\begin{tabular}{|c|c|c|c|}
\hline \multirow[b]{2}{*}{ Advertising strategy } & \multicolumn{3}{|c|}{ Component } \\
\hline & For kids & Price and discount & Celebrity/Commemorative dates \\
\hline \multicolumn{4}{|l|}{ Power of advertising } \\
\hline Celebrity (non-sports) & -0.15 & -0.07 & 0.49 \\
\hline Cartoon/company-owned character & 0.33 & 0.06 & -0.08 \\
\hline 'For kids' & 0.36 & 0.04 & 0.02 \\
\hline Licensed character & 0.36 & 0.07 & 0.05 \\
\hline Non-sports/historical events/festivals & -0.08 & -0.13 & 0.59 \\
\hline Movie tie-in & 0.31 & 0.08 & 0.03 \\
\hline \multicolumn{4}{|l|}{ Premium offers } \\
\hline Price discount & -0.14 & 0.60 & -0.08 \\
\hline Limited edition & 0.33 & 0.00 & -0.18 \\
\hline Gift or collectable & 0.37 & 0.07 & 0.03 \\
\hline \multicolumn{4}{|l|}{ Brand benefit claims } \\
\hline Sensory-based characteristics & -0.22 & -0.02 & -0.22 \\
\hline New brand development & -0.15 & -0.30 & -0.38 \\
\hline Price & -0.14 & 0.60 & -0.08 \\
\hline Suggested users are children or the whole family & 0.34 & 0.03 & -0.04 \\
\hline Convenience & -0.15 & 0.27 & -0.02 \\
\hline Emotive claims & $0 \cdot 11$ & 0.25 & 0.40 \\
\hline
\end{tabular}

Note: The values in bold represent a correlation greater than 0.30 or lesser than -0.30 .

On Facebook, the use of interactive games, apps, celebrities, licensed characters and sportspersons was noted on 27 pages of food brands in Australia, including pages from seven fast-food chains companies ${ }^{(20)}$. In New Zealand and Thailand, the use of hashtags on Facebook posts and the presence of athletes, sports teams and premium offers were also common ${ }^{(26,27)}$. On Instagram, 15 accounts of food brands, seven from fast-food chains, advertised brand elements (logos, colours, fonts, trademarks or slogans) ${ }^{(29)}$. On YouTube, studies from Malaysia and New Zealand have shown the high use of discounts, premium offers, the launch of new products and claims for flavours in videos posted by food brands ${ }^{(28,29)}$.

In addition to these social media, other platforms such as Twitter and Twitch have become increasingly popular and contain food advertising. On Twitter, food and beverage brands create entertaining human personalities for their social media accounts as a powerful advertising tool for attracting young adults. The strategies used most included humour, trendy language and trending topics ${ }^{(30)}$. On Twitch, although there are still no studies that characterise the advertising strategies on this emerging platform, a recent study demonstrates that food and beverage brands accumulate millions of hours of exposure ${ }^{(31)}$ and that food marketing exposures on this platform influence consumption and users' purchasing behaviours ${ }^{(32)}$.

In Brazil, a study pointed out that the fast-food brand studied in this investigation was one of the most popular commercial pages on Facebook in terms of the number of followers ${ }^{(14)}$. In addition, a recent study showed that this 
fast-food chain was among 18 food brands with the highest number of advertisements on TV and three social media platforms in Brazil ${ }^{(15)}$. The present investigation innovates on this subject by analysing the advertising patterns of this company on three social media platforms.

To the best of our knowledge, only two studies focusing on TV advertising have applied PCA to identify food advertising patterns in $\mathrm{Brazil}^{(24,25)}$. One of them found five advertising patterns called distinction, for kids, price and discount, sportive and innovation by applying the INFORMAS protocol for food promotion monitoring ${ }^{(24)}$. Compared to our results, only the sportive component was not identified in the fast-food brand posts, which can be explained by the proximity of the 2018 FIFA World Cup to the data collection period adopted by Santana et al. ${ }^{(24)}$. Another study applied PCA to identify patterns of abusive marketing techniques based on two Brazilian regulations and the INFORMAS protocol and found five patterns, of which four were specifically directed to children or adolescents ${ }^{(25)}$.

Therefore, similar to the advertising pattern on Brazilian television, posts from the fast-food chain in this study on three social media were commonly directed to children and talked about price, discounts and the celebrities' universe. On Facebook and Instagram posts, the brand exalted the characteristics of its products.

Children are considered highly vulnerable to marketing content because they cannot differentiate persuasive content from informative content ${ }^{(9,10)}$. Although social media commonly impose restrictions on children's access, these limits are overridden by omitting real age or accessing the content without signing in (applies to YouTube). A Brazilian survey carried out in 2018 showed that among 24.3 million children aged 9-17 years who mentioned that they access the Internet, 20 million $(82 \%)$ have a social media account ${ }^{(33)}$. This is concerning because when using digital media, their data may be tracked and commercialised. This raises issues not only around privacy violations but also around behavioural manipulation by exploiting children's vulnerability to digital marketing ${ }^{(34)}$.

Thus, our results reinforce the recommendation made by health organisations around the world to implement restrictions on food advertising directed at children ${ }^{(11,35,36)}$. According to the World Health Organization Regional Office for Europe, children have the right to participate in digital media, and when they are participating, they have the right to protect their health and privacy and not to be economically exploited ${ }^{(35)}$. The World Cancer Research Fund International states that protecting children from harmful marketing practices is a human rights issue: governments have to protect, respect and fulfil children's right to health, and marketing of products high in fat, sugar and salt can be framed as a child rights matter, encompassing rights such as the right to health, privacy and information $^{(36)}$
In Brazil, the Consumer Defense Code (Código de Defesa do Consumidor-CDC) of 1990 considers advertisements that take advantage of the child's judgement and experience as illegal ${ }^{(37)}$. In addition, Resolution 163/2014 of the National Council for the Rights of Children and Adolescents (Conselho Nacional dos Direitos da Criança e do Adolescente - Conanda) interprets CDC prohibition and describes the types of abusive advertising directed at children who intend to persuade them to consume or buy any products or services, which includes several of the advertising strategies in this study ${ }^{(38)}$.

Thus, it is evident that Brazilian legislation restricting advertising targeted at children's is ineffective. To move forward on this agenda, the Brazilian State should prioritise comprehensive national policies that protect the exposure of children to the advertising content, adapt and extend the legislation to the digital environment, develop high-tech monitoring tools and appropriate sanctions and penalty mechanisms for both creators of marketing content and dissemination platforms when there are irregularities ${ }^{(35)}$. Additionally, food and beverage companies must adapt their marketing practices to state legislation, since prior research has pointed out the ineffectiveness of autoregulation and civil responsibility ${ }^{(36,39)}$.

Regarding the appeal of fast-food chain posts on price, discounts and product characteristics, they focused on coupons, combos (a combination of food items and drinks offered at a discount), free delivery (in case of delivery services), low prices, high portions, convenience and great satisfaction. However, this approach was not similar for all social media platforms. On Instagram, the brand associated the economic claim with the practical appeal and the celebrities' context with innovation in the products. On YouTube, celebrity and commemorative dates were grouped into the same component.

These results highlight that this brand chooses social media strategically to reach a specific consumer that is influenced by specific content. On Instagram, the brand focuses on the products and their characteristics, especially when launching a new or limited-edition product. This platform layout allows the company to share objective information about their products and to mark the address of food outlets. In contrast, YouTube publishes videos with different purposes and longer durations, characterising a platform more indicated for the dissemination of information such as brand history, mission and values, which usually involves emotive claims, but also to disseminate the same advertisements that are spread on television. This can explain the high use of emotive claims by the brand on YouTube videos, in addition to the diversified use of marketing strategies.

Therefore, in addition to limiting the exposure of children to digital food advertising content, it is necessary to strengthen the discussion about ultra-processed food companies' exchange with the public. People of all ages are vulnerable to the marketing content of ultra-processed 
food companies and the consequences of consumption of this kind of product ${ }^{(8,40)}$. Restricting the advertising of food with a high content of sodium, saturated fat, added sugars and other nutrients is a measure of protecting all individuals from the advertising of unhealthy foods. For example, in Chile and Peru, in any advertisements of food items that are not aligned with a nutrient profile model must display sentences in a clear, legible, highlighted and understandable form about the harmful consequences of consuming these products regularly ${ }^{(41-43)}$. In Brazil, these alerts will soon be implemented on the front of food packaging due to a recently passed food labelling regulation ${ }^{(44)}$; however, the legislation does not include restrictions or warnings on food advertisements. Therefore, it is necessary to implement a policy with a comprehensive marketing restriction, including food labelling and food advertising, ensuring more efficiency in preventing the exposure of individuals to unhealthy food advertising.

Finally, it is important to mention the limitations of the study results. First, we have studied a single brand and the advertising patterns identified may not represent the pattern of other brands, although a great similarity has been found with other studies that have described food advertising on Brazilian television ${ }^{(24,25)}$ and social media ${ }^{(14,15)}$. Evaluating the food advertising practices of other companies would support the generalisability of the findings. Second, the INFORMAS food promotion protocol was adopted, although it was proposed for food advertising monitoring on TV. However, the advertising strategies studied by this protocol are also commonly studied in social media investigations ${ }^{(15,20-22)}$. In addition, collecting marketing strategies is a task with high subjectivity, which was minimised in the present study by applying doublecoded data collection and correcting all divergences.

In sum, this study showed, for the first time, the advertising patterns presented on fast-food chain social media accounts. Since the majority of the products promoted were ultra-processed foods, the high exposure of individuals to this persuasive content is of concern. Future studies can address whether pages from other ultra-processed companies contain the same advertising patterns and elucidate how this content can impact an individual's food behaviour. These findings have the potential to guide policy responses.

\section{Acknowledgements}

Acknowledgements: None. Financial support: This research received no specific grant from any funding agency, commercial or not-for-profit sectors. Conflict of interest: There are no conflicts of interest. Authorship: J.M.S.: Conceptualisation; methodology; investigation; writing (original draft) , J.P.M.: Conceptualisation; methodology; investigation; writing (review and editing), M.B.R.:
Conceptualisation; methodology; investigation; writing (review and editing), L.A.M: Conceptualisation; methodology; writing (review and editing), R.M.C.: Conceptualisation; methodology; investigation; writing (review and editing), P.M.H.: Conceptualisation; methodology; investigation; data curation; formal analysis; writing (review and editing); supervision. Ethics of human subject participation: This study does not involve human participants.

\section{Supplementary material}

For supplementary material/s referred to in this article, please visit https://doi.org/10.1017/S1368980021004973

\section{References}

1. Martins APB, Levy RB, Claro RM et al. (2013) Increased contribution of ultra-processed food products in the Brazilian diet (1987-2009). Rev Saúde Pública 47, 1-10.

2. Brasil 2020 (2020) Consumer Expenditure Survey 2017-2018: Analysis of Personal Food Consumption in Brazil. Rio de Janeiro: IBGE.

3. Monteiro CA, Cannon G, Lawrence M et al. (2019) UltraProcessed Foods, Diet Quality, and Health Using the NOVA Classification System. Rome: FAO.

4. Andrade GC, Gombi-Vaca MF, Louzada MLDC et al. (2020) The consumption of ultra-processed foods according to eating out occasions. Public Health Nutr 23, 1041-1048.

5. Kelly B, Vandevijvere S, Ng S et al. (2019) Global benchmarking of children's exposure to television advertising of unhealthy foods and beverages across 22 countries. Obes Rev 2, 116-128.

6. Tatlow-Golden M, Jewell J, Zhiteneva O et al. (2021) Rising to the challenge: introducing protocols to monitor food marketing to children from the World Health Organization Regional Office for Europe. Obes Rev 22, e13212.

7. Close JP \& Ham J (2016) Persuasive Communication. AiREAS: Sustainocracy for a Healthy City: Phase 3: Civilian Participation - Including the Global Health Deal Proposition. Cham: Springer.

8. Buchanan L, Kelly B, Yeatman H et al. (2018) The effects of digital marketing of unhealthy commodities on young people: a systematic review. Nutrients 10, 148 .

9. Carter OB, Patterson LJ, Donovan RJ et al. (2011) Children's understanding of the selling versus persuasive intent of junk food advertising: implications for regulation. Soc Sci Med 72, 962-968.

10. Smith R, Kelly B, Yeatman H et al. (2019) Food marketing influences children's attitudes, preferences and consumption: a systematic critical review. Nutrients 11, 875.

11. UNSCN (2020) United Nations System Standing Committee on Nutrition 2020. Nutrition in a Digital Word 45. https:// www.unscn.org/en/Unscn-news?idnews $=2082$ (accessed November 2021).

12. IBOPE (2016) Brazilian Media Research-2016. Presidência da República. Secretaria de Comunicação Social. Assessoria de Pesquisa de Opinião Pública. Brasília: Agosto.

13. IBOPE (2018) Social media apps are the most used on smartphones. http://ibopeconecta.com/apps-de-redes-sociais-saoos-mais-usados-em-smartphones/ (accessed December 2019).

14. Horta PM \& Rodrigues FT \& dos Santos LC (2018) Ultra-processed food product brands on Facebook pages: 
highly accessed by Brazilians through their marketing techniques. Public Health Nutr 21, 1515-1519.

15. Silva JM, Rodrigues MB, Matos JP et al. (2021) Use of persuasive strategies in food advertising on television and on social media in Brazil. Prev Med Rep 24, 101520.

16. Kelly B, King L, Baur L et al. (2013) Monitoring food and non-alcoholic beverage promotions to children. Obes Rev 14, 59-69.

17. Statista (2020) Preferred Fast-Food Restaurants among Internet Users in Brazil in 2019. https://www.statista.com/ statistics/1114385/fast-food-restaurants-brazil/ （accessed December 2019).

18. Voorveld HAM (2019) Brand communication in social media: a research agenda. $J$ Advert $\mathbf{4 8}, 14-26$.

19. Kelly B (2017) Food Marketing - Television: INFORMAS Food Promotion Protocol. University of Auckland. https:// www.informas.org/modules/food-promotion/ (accessed December 2019).

20. Freeman B, Kelly B, Baur L et al. (2014) Digital junk: food and beverage marketing on Facebook. Am J Public Health 104, e56-e64.

21. Brownbill AL, Miller CL \& Braunack-Mayer AJ (2018) The marketing of sugar-sweetened beverages to young people on Facebook. Aust NZ J Public Health 42, 354-360.

22. Bragg MA, Pageot YK, Amico A et al. (2020) Fast food, beverage, and snack brands on social media in the United States: an examination of marketing techniques utilized in 2000 brand posts. Pediatr Obes 15, e12606.

23. Jolliffe IT \& Cadima J (2019) Principal component analysis: a review and recent developments. Phil Trans $R$ Soc A374, 20150202.

24. Santana MO, Guimarães JS, Leite FHM et al. (2020) Analysing persuasive marketing of ultra-processed foods on Brazilian television. Int J Public Health 65, 1067-1077.

25. Guimarães JS, Mais LA, Leite FHM et al. (2021) Abusive advertising of food and drink products on Brazilian television. Health Promot Int, daab025. doi: 10.1093/heapro/ daab025.

26. Vandevijvere S, Aitken C \& Swinburn B (2018) Volume, nature and potential impact of advertisements on Facebook and YouTube by food brands popular in New Zealand. NZ Med J 131, 14-24.

27. Jaichuen N, Vongmongkol V, Suphanchaimat R et al. (2019) Food Marketing in Facebook to Thai children and youth: an assessment of the efficacy of Thai Regulations. Int J Environ Res Public Health 16, 1204.

28. Tan L, Ng SH, Omar A et al. (2018) What's on YouTube? A case study on food and beverage advertising in videos targeted at children on social media. Child Obes $\mathbf{1 4}$, 280-290.

29. Vassallo AJ, Kelly B, Zhang L et al. (2018) Junk food marketing on Instagram: content analysis. JMIR Public Health Surveill 4, e54.

30. Greene T, Seet C, Rodríguez Barrio A et al. (2021) Brands with personalities - good for businesses, but bad for public health? A content analysis of how food and beverage brands personify themselves on Twitter. Public Health Nutr, 1-10. doi: 10.1017/S1368980021001439.

31. Pollack C, Kim J, Emond J et al. (2020) Prevalence and strategies of energy drink, soda, processed snack, candy and restaurant product marketing on the online streaming platform Twitch. Public Health Nutr 23, 2793-2803.

32. Pollack C, Gilbert-Diamond D, Emond J et al. (2021) Twitch user perceptions, attitudes and behaviours in relation to food and beverage marketing on Twitch compared with YouTube. J Nutr Sci 10, E32.

33. TIC Kids Online (2018) Centro Regional de Estudos para o Desenvolvimento da Sociedade da Informação (Cetic.br).
Survey on Internet Use by Children in Brazil: ICT KIDS ONLINE BRAZIL. https://cetic.br/ (accessed December 2019).

34. Tatlow-Golden M \& Garde A (2020) Digital food marketing to children: exploitation, surveillance and rights violations. Global Food Secur 27, 100423.

35. WHO. World Health Organization Europe (2016) Tackling Food Marketing to Children in a Digital World: Trans-Disciplinary Perspectives. http://www.euro.who.int/ en/health-topics/disease-prevention/nutrition/publications/ 2016/tackling-food-marketing-to-children-in-a-digital-worldtrans-disciplinary-perspectives-2016 (accessed November 2021).

36. WCRF 2020 (2020) World Cancer Research Fund International. Building Momentum: Lessons on Implementing Robust Restrictions of Food and NonAlcoholic Beverage Marketing to Children. London: WCRFI. https://www.wcrf.org/sites/default/files/PPABuilding-Momentum-3-WEB-3.pdf (accessed November 2021).

37. Brasil (1990) Law no. 8078 as of September 11, 1990: Consumer Defense Code. Provides for consumers' protection and makes other arrangements. http://www.planalto. gov.br/ccivil_03/Leis/L8078.htm (accessed December 2019).

38. Brasil (2014) Resolution No. 163 on March 13, 2014. Brazil's National Council of the Rights of the Child and the Adolescent (Conselho Nacional dos Direitos da Criança e do Adolescente, or CONANDA). https://crianca.mppr.mp.br/ pagina-1635.html\#resolucao_163 (accessed December 2019).

39. Kraak VI, Vandevijvere S, Sacks G et al. (2016) Progress achieved in restricting the marketing of high-fat, sugary and salty food and beverage products to children. Bull World Health Organ 94, 540-548.

40. Wood B, Williams O, Nagarajan V et al. (2021) Market strategies used by processed food manufacturers to increase and consolidate their power: a systematic review and document analysis. Global Health 17, 1-23.

41. Pérez-Escamilla R, Vilar-Compte M, Rhodes E et al. (2021) Implementation of childhood obesity prevention and control policies in the United States and Latin America: lessons for cross-border research and practice. Obes Rev 22, e13247.

42. República del Perú (Republic of Peru) (2018) Decreto Supremo $\mathrm{N}^{\circ}$ 012-2018-SA. Aprueban Manual de Advertencias Publicitarias en el marco de lo establecido en la Ley $\mathrm{N}^{\circ} 30021$, Ley de promoción de la alimentación saludable para niños, niñas y adolescentes, y su Reglamento aprobado por Decreto Supremo No 017-2017-AS. 16 Jun 2018. El Peruano (Supreme Decree No. 012-2018-SA. The Manual of Advertising Warnings is Approved within the Framework of what is Established in Law No. 30021, Law for the Promotion of Healthy Eating for Children and Adolescents, and its Regulations approved by Supreme Decree No. 017-2017-AS. 16 Jun 2018. The Peruvian). https://cdn. www.gob.pe/uploads/document/file/185531/93706_1.pdf (accessed November 2021).

43. Ministerio de Salud - Subsecretaría de Salud Pública (2012) Ley 20606 - Sobre composición nutricional de los alimentos y su publicidade (Ministry of Health - Undersecretariat of Public Health. Law 20606 - On Nutritional Composition of Foods and its Publicity). https://www.bcn.cl/leychile/ navegar?idNorma $=1041570$ (accessed November 2021).

44. Ministério da Saúde (2020) Agência Nacional de Vigilância Sanitária. Collegiate Board Decision RDC ANVISA No 429, October 8th, 2020. Provides for the nutritional labeling of packaged foods. http://antigo.anvisa.gov.br/documents/ 10181/3882585/RDC_429_2020_.pdf/9dc15f3a-db4c-4d3f90d8-ef4b80537380 (accessed November 2021). 